\title{
Zinc-Catalyzed Regioselective Addition of Alkyl Thiols to Alkenes via Anion or Radical Reactions
}

\author{
Nobukazu Taniguchi \\ Department of Chemistry, Fukushima Medical University, Fukushima 960-1295, Japan \\ Email: taniguti@fmu.ac.jp
}

Dedicated to Prof. Dr. Lanny L. Liebeskind on the occasion of his $70^{\text {th }}$ birthday

Received 12-09-2020

Accepted 02-02-2021

Published on line $02-06-2021$

\begin{abstract}
Zn-catalyzed reactions of alkenes with alkyl thiols could afford alkyl sulfides regioselectively. When the $\mathrm{ZnI}_{2-}$ catalyzed hydrothiolation of alkenes was achieved using alkyl thiols at $100{ }^{\circ} \mathrm{C}$, Markovnikov-type alkyl sulfides were obtained in excellent yields without the formation of linear products. To the contrary, $\mathrm{Zn}(\mathrm{OAc})_{2^{-}}$ catalyzed reaction gave rise only to anti-Markovnikov-type products regioselectively. The reaction proceeded via a radical process.
\end{abstract}

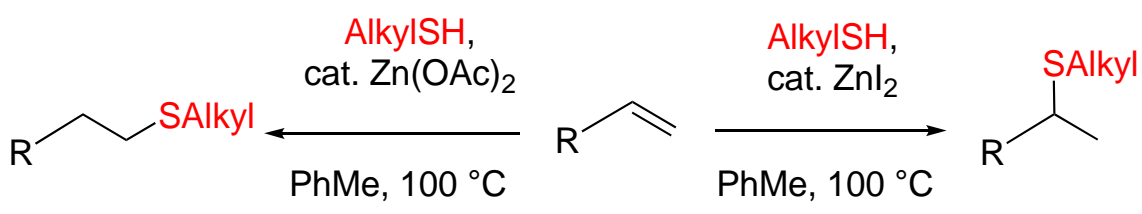

Keywords: Zinc catalyst, Anion, Radical, Alkene, Alkyl thiol 


\section{Introduction}

Transition metal-catalyzed carbon-sulfur bond formations have been exploited by numerous researchers to date; such procedures are widely utilized in organic chemistry. ${ }^{1-5}$ Among them, hydrothiolation of alkenes has been well investigated. ${ }^{6-12}$ The reaction usually produces two regioisomers. Development of regioselective reactions is greatly to be desired.

As a general rule, arenethiols readily generate thiyl radicals in the presence of oxygen or light; however their formation from alkyl thiols is very slow (Figure 1). ${ }^{13}$ To generate alkyl thiyl radicals, irradiation using UV or blue light in the presence of metal catalysts is required. Various procedures have been successful to date. ${ }^{14-16}$ For example, the Ru-catalyzed reaction performed under irradiation with blue light affords anti-Markovnikov-type products in excellent yields. ${ }^{14,15}$ Contrarily, alkyl thiols work as anion sources without light irradiation. ${ }^{17-22}$ For instance, In- or Mont K10-catalyzed reactions of alkenes with alkyl thiols afford Markovnikov-type products regioselectively (Scheme 1). ${ }^{17,22}$

Recently, it was reported that the $\mathrm{ZnI}_{2}$-catalyzed reactions of aryl alkenes with thiols produces Markovnikovtype sulfides regioselectively in the presence of 4-toluenesulfonic acid. ${ }^{23}$ This method cannot afford radical reaction products, whereas zinc salts have the ability to promote radical reactions ${ }^{24,25}$ thus, various zinc salts were screened. Fortunately, on one hand, it was found that $\mathrm{ZnI}_{2}$-catalyzed reactions using alkyl thiols afforded Markovnikov-type products in the absence of 4-toluenesulfonic acid. On the other hand, $\mathrm{Zn}(\mathrm{OAc})_{2}$-catalyzed reactions produced anti-Markovnikov-type sulfides. In this paper, these methods are described.

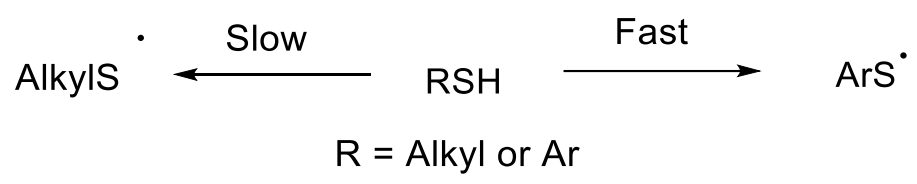

Figure 1. The formation of thiyl radicals.
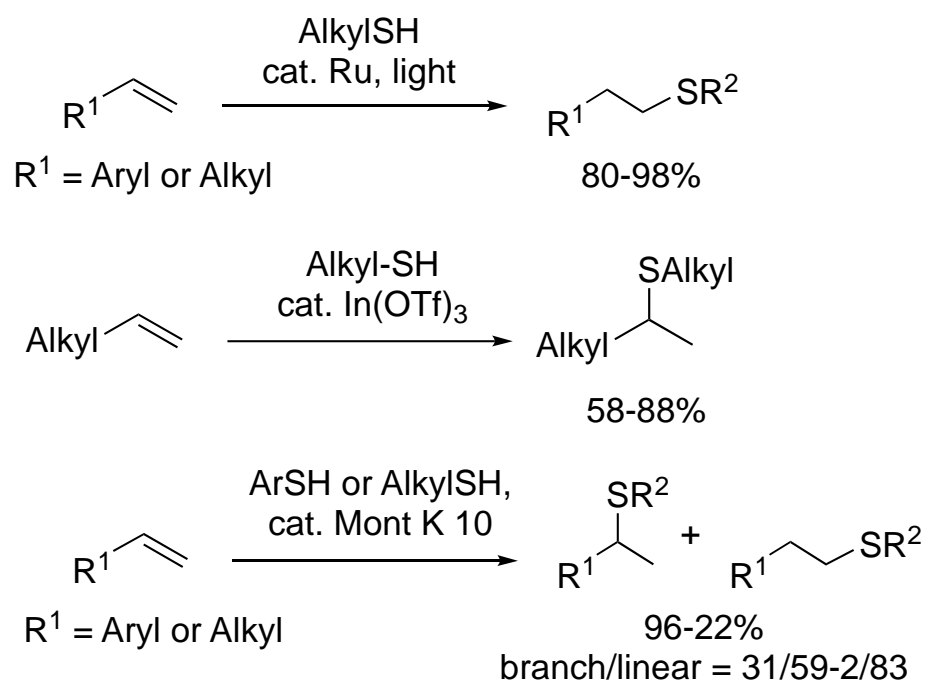

Scheme 1. Reported reactions of alkenes with alkyl thiols. 


\section{Results and Discussion}

To establish the hydrothiolation of alkenes using alkyl thiols, various conditions were investigated. As shown in Table 1, when the $\mathrm{ZnI}_{2}$-catalyzed reaction of styrene with 1-butanethiol was performed in dichloromethane or toluene at room temperature, the expected sulfide 2 was not obtained (Entries 1-2). Also the reaction did not proceed in acetic acid at $100{ }^{\circ} \mathrm{C}$ did not proceed (Entry 3). However, when the solvent was changed to toluene, the corresponding branched sulfide $\mathbf{3}$ was obtained in a 79\% yield without the formation of other products (Entry 4). Similarly, the reaction using $\mathrm{ZnBr}_{2}$ produced the same result (Entry 5). Notably, the reactions using $\mathrm{ZnF}_{2}$ or $\mathrm{Zn}(\mathrm{OAc})_{2}$ catalysts afforded linear sulfide 3 in $38 \%$ or $49 \%$ yields, regioselectively (Entry 7). Furthermore, when the $\mathrm{Zn}(\mathrm{OAc})_{2}$-catalyzed reaction was performed for $36 \mathrm{~h}$, the production of $\mathbf{3}$ increased to $87 \%$ yield (Entry 9). The reactivity of other metal catalysts were examined similarly, but these led to unsatisfactory results (Entries 10-14).

Table 1. Investigation of suitable conditions ${ }^{a}$
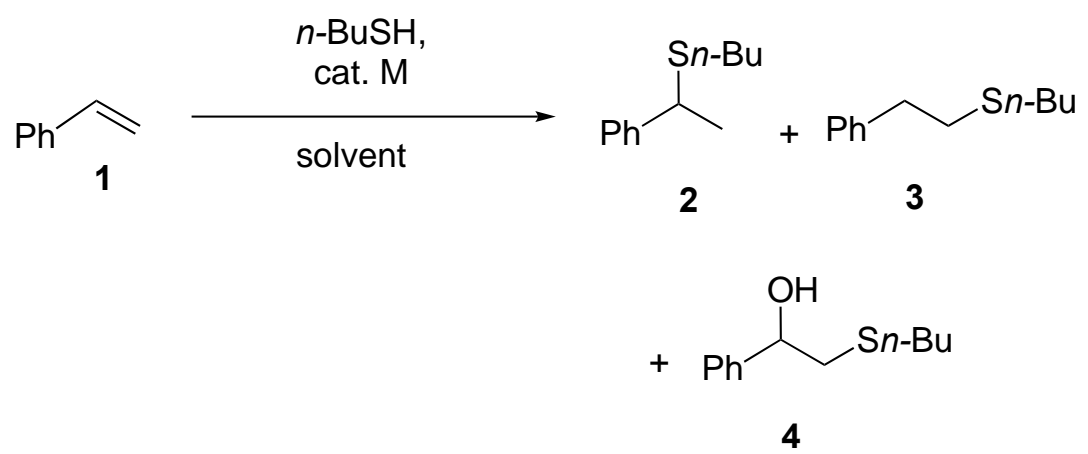

\begin{tabular}{|c|c|c|c|c|c|c|}
\hline Entry & solv. & $\mathrm{M}$ & $\stackrel{\circ}{C}$ & $2 / 3 / 4^{b}$ & $2(\%)^{c}$ & $3(\%)^{c}$ \\
\hline 1 & $\mathrm{CH}_{2} \mathrm{Cl}_{2}$ & $\mathrm{ZnI}_{2}$ & $\mathrm{rt}$ & $0 / 100 / 0$ & 0 & trace \\
\hline 2 & PhMe & $\mathrm{ZnI}_{2}$ & $\mathrm{rt}$ & $0 / 100 / 0$ & 0 & trace \\
\hline 3 & $\mathrm{AcOH}$ & $\mathrm{ZnI}_{2}$ & 100 & - & 0 & 0 \\
\hline 4 & PhMe & $\mathrm{ZnI}_{2}$ & 100 & $100 / 0 / 0$ & 79 & 0 \\
\hline 5 & PhMe & $\mathrm{ZnBr}_{2}$ & 100 & $100 / 0 / 0$ & 77 & 0 \\
\hline 6 & PhMe & $\mathrm{ZnCl}_{2}$ & 100 & $91 / 9 / 0$ & 27 & trace \\
\hline 7 & PhMe & $\mathrm{ZnF}_{2}$ & 100 & $0 / 100 / 0$ & 0 & 38 \\
\hline 8 & PhMe & $\mathrm{Zn}(\mathrm{OAc})_{2}$ & 100 & $0 / 100 / 0$ & 0 & 49 \\
\hline $9^{d}$ & PhMe & $\mathrm{Zn}(\mathrm{OAc})_{2}$ & 100 & $0 / 100 / 0$ & 0 & 87 \\
\hline 10 & PhMe & $\mathrm{NiCl}_{2}$ & 100 & $0 / 75 / 25$ & 0 & 17 \\
\hline 11 & PhMe & $\mathrm{NiBr}_{2}$ & 100 & 9/91/0 & trace & 41 \\
\hline 12 & PhMe & $\mathrm{FeBr}_{3}$ & 100 & $100 / 0 / 0$ & 51 & 0 \\
\hline 13 & PhMe & $\mathrm{CuBr}_{2}$ & 100 & $95 / 5 / 0$ & 16 & trace \\
\hline 14 & PhMe & Cul & 100 & $0 / 75 / 25$ & 0 & 17 \\
\hline
\end{tabular}

${ }^{a}$ Reaction conditions: A mixture of $1(0.3 \mathrm{mmol}), n$-BuSH $(0.33 \mathrm{mmol})$ and cat. $\mathrm{M}(10 \mathrm{~mol} \%)$ in solvent $(0.3 \mathrm{~mL})$. ${ }^{\text {b}}$ Determined by ${ }^{1} \mathrm{H}$ NMR. ${ }^{\text {I Isolated }}$ yield after silica gel chromatography. ${ }^{\mathrm{d}}$ The reaction was performed for 36 h. 
Table 2. Zn-catalyzed hydrothiolation of alkenes ${ }^{a}$
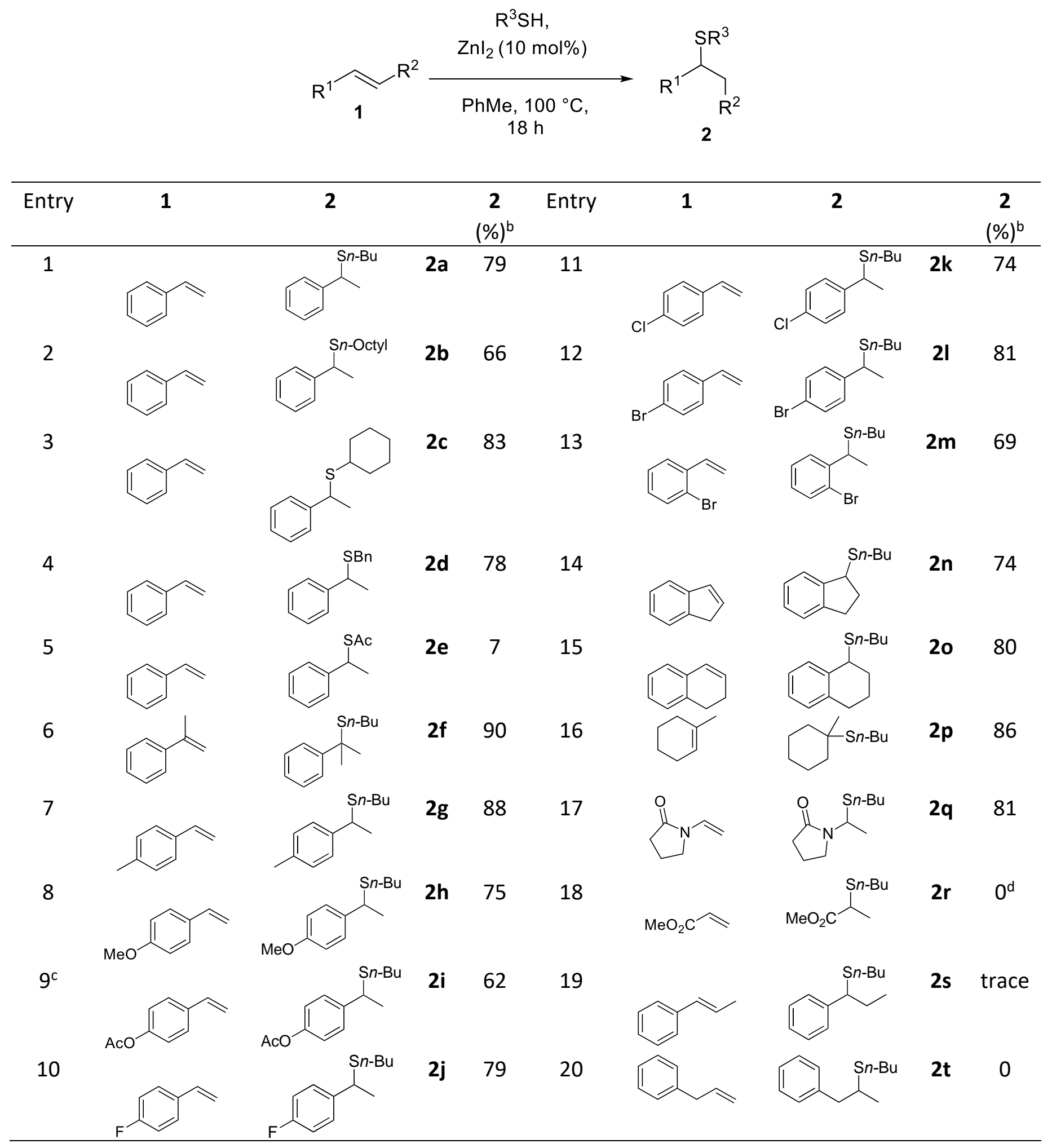
Table 2. Continued

aReaction conditions: A mixture of $1(0.3 \mathrm{mmol}), \mathrm{R}^{3} \mathrm{SH}(0.33 \mathrm{mmol})$ and $\mathrm{ZnI}_{2}(10 \mathrm{~mol} \%)$ in PhMe $(0.15 \mathrm{~mL})$ was heated at $100 \stackrel{\circ}{\circ}$. ' Isolated yield after silica gel chromatography. The reaction was performed for $42 \mathrm{~h}$. dMethyl 3-(1-butylthio)propionate was obtained in 90\% yield.

Sequentially, the $\mathrm{Zn}(\mathrm{OAc})_{2}$-catalyzed reactions were also surveyed for the preparation of anti-Markovnikovtype sulfides (Table 3). When a mixture of alkene with alkyl thiol was heated at $100{ }^{\circ} \mathrm{C}$ for $36 \mathrm{~h}$, the expected products 3 were regioselectively obtained in excellent yields (Entries 1-5). Similarly, the procedure worked with various styrene derivatives (Entries 6-9). Regrettably, using internal or terminal alkyl alkenes produced lower yields (Entries 10-12).

On the basis of developed procedure, numerous substrates were next investigated (Table 2). When styrene was reacted with different alkyl thiols, the expected products were obtained in excellent yields without the formation of linear sulfides (Entries 1-6). Numerous styrene derivatives were suitable substrates for the procedure (Entries 7-13). Furthermore, cyclic alkenes afforded $\mathbf{2}$ in excellent yields, regioselectively (Entries 14-16). A using vinyl pyrrolidine gave only the expected sulfide 2 with an $81 \%$ yield (Entry 17). On the other hand, the reaction of methyl acrylate produced linear products in a $90 \%$ yield (Entry 18). Regrettably, other internal alkenes or terminal alkyl alkenes did not undergo the reaction satisfactorily (Entries 19-20).

Table 3. Zn-catalyzed hydrothiolation of alkenes ${ }^{a}$

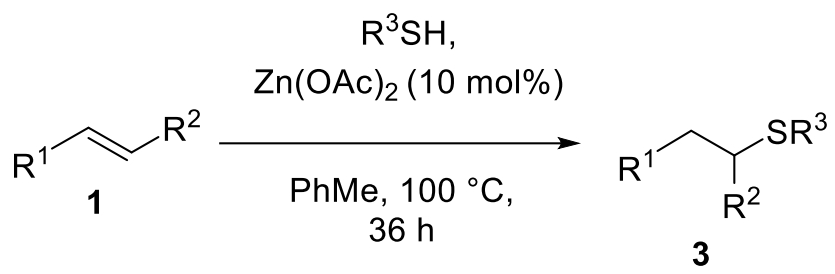

Entry

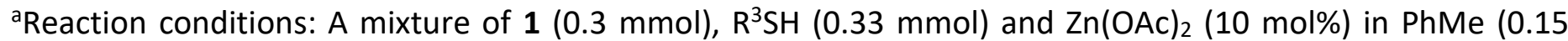
$\mathrm{mL}$ ) was heated at $100 \stackrel{\circ}{\circ} \mathrm{C}$. ' Isolated yield after silica gel chromatography. ${ }^{\mathrm{C}}$ Determined by ${ }^{1} \mathrm{H} N \mathrm{NM}$. 
To clarify these reaction mechanisms, several experiments were then carried out. Initially, the reactions were performed in the presence of 2,6-di-tert-butyl-4-methylphenol (BHT) as a radical scavenger (Scheme 2). Although the $\mathrm{ZnI}_{2}$-catalyzed reactions gave the corresponding product in an $80 \%$ yield, $\mathrm{Zn}(\mathrm{OAc})_{2}$ did not promote the reaction. These results indicate that the reaction using $\mathrm{Zn}(\mathrm{OAc})_{2}$ as catalyst might involve a radical process. Furthermore, reactions in the absence of oxygen were also examined. When a mixture of styrene with 1-butanethiol was treated by $\mathrm{ZnI}_{2}$ under an argon atmosphere, the corresponding sulfide $2 \mathrm{a}$ was obtained in a $77 \%$ yield. However, again, $\mathrm{Zn}(\mathrm{OAc})_{2}$ catalysis did not occur (Scheme 3). It is conceivable that the thiyl radicals are generated in the presence of oxygen.

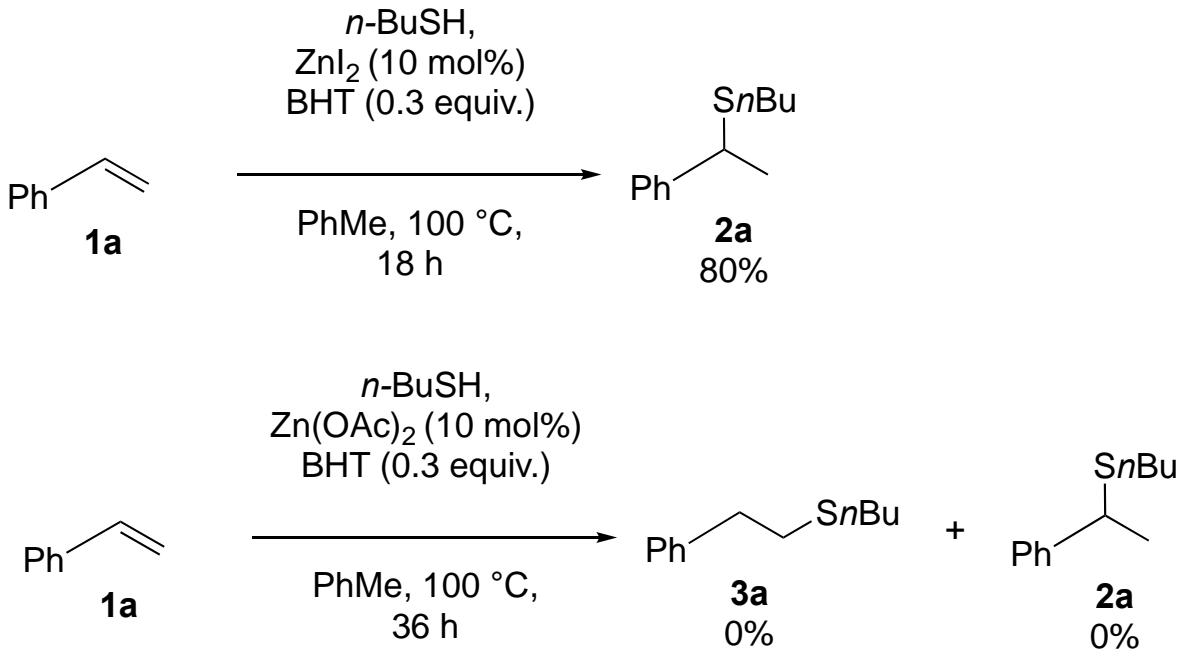

Scheme 2. A reaction in the presence of BHT.
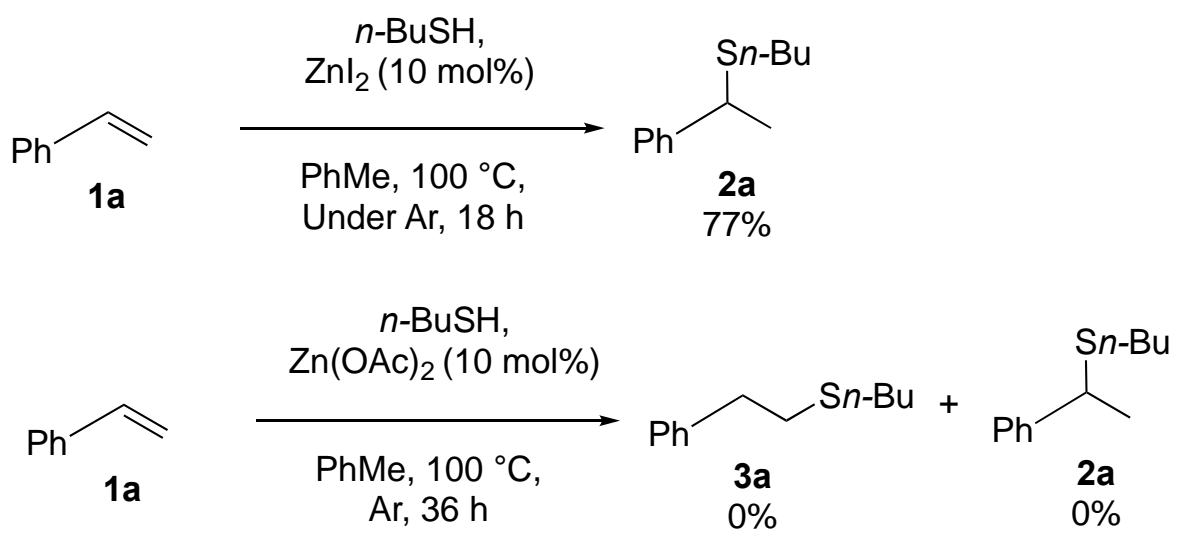

Scheme 3. A reaction in the absence of oxygen.

From these results, a plausible reaction mechanism is considered to be as follows (Figure 2 ). ${ }^{11} \ln$ the $\mathrm{Znl} 2^{-}$ catalyzed reaction, after the reaction of $\mathrm{Znl}_{2}$ with the alkyl thiol produces an alkylS-ZnI complex, ${ }^{9}$ Markovnikov-type products are produced by the addition of the complex to the alkene. Alternatively, in reactions using a $\mathrm{Zn}(\mathrm{OAc})_{2}$ catalyst in oxygen, thiyl radicals are efficiently produced. Ultimately, antiMarkovnikov-type products are obtained. 


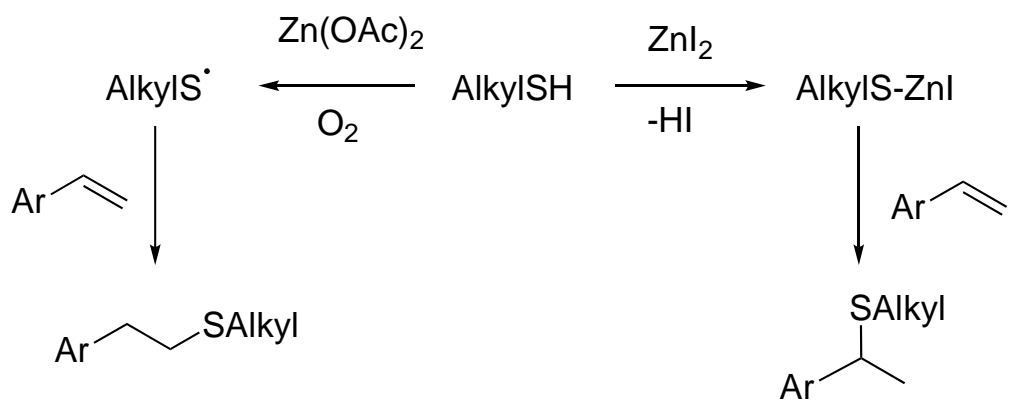

Figure 2. A plausible reaction mechanism.

\section{Conclusions}

In conclusion, the $\mathrm{Znl}_{2}$-catalyzed hydrothiolation of alkenes using alkyl thiols was achieved at $100{ }^{\circ} \mathrm{C}$. The procedure regioselectively affords excellent yields of Markovnikov-type products. However, Zn(OAc) catalyzed hydrothiolation regioselectively produces anti-Markovnikov-type products via a radical process. Thus, regioselective additions of alkyl thiols to alkenes were achieved using different zinc catalysts.

\section{Experimental Section}

General Procedure and Chemicals. All reactions were carried out in air. ${ }^{1} \mathrm{H}$ and ${ }^{13} \mathrm{C}$ NMR spectra were recorded on a JEOL EX-270 spectrometer $\left(270 \mathrm{MHz}\right.$ for ${ }^{1} \mathrm{H}, 67.8 \mathrm{MHz}$ for ${ }^{13} \mathrm{C}$ ). Chemical shifts are reported in $\delta$ ppm referenced to an internal tetramethylsilane standard for ${ }^{1} \mathrm{H} N M R$ and chloroform-d $(\delta 77.0)$ for ${ }^{13} \mathrm{C} \mathrm{NMR}$. IR spectra were recorded on a PerkinEImer Frontier FT-IR spectrometer.

Typical procedure for zinc-catalyzed hydrothiolation of alkenes: Synthesis of 1-(1-Butylthio)-1-phenylethane (2a) (Table 2, entry 1)

To a mixture of styrene (31.2 mg, $0.3 \mathrm{mmol}), 1$-butanethiol $(56.8 \mathrm{mg}, 0.33 \mathrm{mmol})$, in $\mathrm{PhCH}_{3}(0.3 \mathrm{~mL}), \mathrm{Znl} 2(9.6$ $\mathrm{mg}, 0.03 \mathrm{mmol}$ ) was added, and the mixture was stirred at $100{ }^{\circ} \mathrm{C}$ for $18 \mathrm{~h}$ in the presence of air in $15 \mathrm{~mL}$ glass test tube with plastic screw cap. After, the residue was dissolved in $\mathrm{Et}_{2} \mathrm{O}$, the solution was washed with $\mathrm{H}_{2} \mathrm{O}$ and saturated aq $\mathrm{NaCl}$ and dried over anhydrous $\mathrm{MgSO}_{4}$. Chromatography on silica gel (hexane) gave 1-(1butylthio)-1-phenylethane $2 \mathrm{a}(45.9 \mathrm{mg}, 79 \%)$ : Colorless oil; ${ }^{1} \mathrm{H} \mathrm{NMR}\left(270 \mathrm{MHz}, \mathrm{CDCl}_{3}\right) \delta 7.36-7.20(\mathrm{~m}, 5 \mathrm{H}, \mathrm{Ar}-$ $\mathrm{H}), 3.94(\mathrm{q}, J=7.0 \mathrm{~Hz}, 1 \mathrm{H}, \mathrm{CH}), 2.34-2.24\left(\mathrm{~m}, 2 \mathrm{H}, \mathrm{CH}_{2}\right), 1.56\left(\mathrm{~d}, J=7.0 \mathrm{~Hz}, 3 \mathrm{H}, \mathrm{CH}_{3}\right), 1.53-1.38\left(\mathrm{~m}, 2 \mathrm{H}, \mathrm{CH}_{2}\right)$, 1.38-1.27 (m, $\left.2 \mathrm{H}, \mathrm{CH}_{2}\right), 0.84\left(\mathrm{t}, J=7.2 \mathrm{~Hz}, 3 \mathrm{H}, \mathrm{CH}_{3}\right) ;{ }^{13} \mathrm{C}\left\{{ }^{1} \mathrm{H}\right\} \mathrm{NMR}\left(67.8 \mathrm{MHz}, \mathrm{CDCl}_{3}\right) \delta 144.2,128.4,127.2,126.9$, 44.0, 31.4, 30.9, 22.6, 22.0, 13.6; IR (neat, $\mathrm{NaCl}$ cell, $v_{\text {max }} \mathrm{cm}^{-1}$ ) 2959 (C-H), 2927 (C-H), 1602 (C=C), 1491 (C=C), 1451 (C-H), 1373 (C-H), 1217 (SC-H); Anal. Calcd for $\mathrm{C}_{12} \mathrm{H}_{18} \mathrm{~S}$ (194.34): C, 74.17; H, 9.34. Found: C, 73.88; H, 9.28 .

1-(1-Octylthio)-1-phenylethane (2b). The title compound was obtained as a colorless oil (49.2 mg, 66\%). ${ }^{1} \mathrm{H}$ $\operatorname{NMR}\left(270 \mathrm{MHz} \mathrm{CDCl}_{3}\right) \delta$ 7.36-7.19 (m, 5H, Ar-H), $3.94(\mathrm{q}, J=7.0 \mathrm{~Hz}, 1 \mathrm{H}, \mathrm{CH}), 2.38-2.21\left(\mathrm{~m}, 2 \mathrm{H}, \mathrm{CH}_{2}\right), 1.57(\mathrm{~d}, J$ $\left.=7.0 \mathrm{~Hz}, 3 \mathrm{H}, \mathrm{CH}_{3}\right), 1.48-1.43\left(\mathrm{~m}, 2 \mathrm{H}, \mathrm{CH}_{2}\right), 1.31-1.22\left(\mathrm{~m}, 10 \mathrm{H}, \mathrm{CH}_{2}\right), 0.87\left(\mathrm{t}, J=6.8 \mathrm{~Hz}, 3 \mathrm{H}, \mathrm{CH}_{3}\right) ;{ }^{13} \mathrm{C}\left\{{ }^{1} \mathrm{H}\right\} \mathrm{NMR}$ $\left(67.8 \mathrm{MHz}_{2} \mathrm{CDCl}_{3}\right) \delta 144.2,128.4,127.2,126.9,44.0,31.8,31.3,29.3,29.1,28.9,22.6,22.5,14.1 ; \mathrm{IR}$ (neat, $\mathrm{NaCl}$ 
cell, $\left.V_{\max }, \mathrm{cm}^{-1}\right) 2925$ (C-H), $2854(\mathrm{C}-\mathrm{H}), 1602$ (C=C), 1491 (C=C), 1452 (C-H), 1372 (C-H), 1220 (S C-H), 1026 (CH); Anal. Calcd for $\mathrm{C}_{16} \mathrm{H}_{26} \mathrm{~S}$ (264.47): C, 76.73; H, 10.46. Found: C, 76.77; H, 10.48.

1-Cyclohexylthio-1-phenylethane (2c). The title compound was obtained as a colorless oil $(54.8 \mathrm{mg}, 83 \%) .{ }^{1} \mathrm{H}$ NMR $\left(270 \mathrm{MHz}, \mathrm{CDCl}_{3}\right) \delta 7.37-7.18(\mathrm{~m}, 5 \mathrm{H}, \mathrm{Ar}-\mathrm{H}), 4.04(\mathrm{q}, J=7.0 \mathrm{~Hz}, 1 \mathrm{H}, \mathrm{CH}), 2.42-2.34\left(\mathrm{~m}, 1 \mathrm{H}, \mathrm{CH}_{2}\right), 1.99-$ $1.94\left(\mathrm{~m}, 1 \mathrm{H}, \mathrm{CH}_{2}\right), 1.75-1.65\left(\mathrm{~m}, 3 \mathrm{H}, \mathrm{CH}_{2}\right), 1.56-1.53\left(\mathrm{~m}, 1 \mathrm{H}, \mathrm{CH}_{2}\right), 1.55\left(\mathrm{~d}, J=6.9 \mathrm{~Hz}, 3 \mathrm{H}, \mathrm{CH}_{3}\right), 1.40-1.18(\mathrm{~m}$, $\left.5 \mathrm{H}, \mathrm{CH}_{2}\right) ;{ }^{13} \mathrm{C}\left\{{ }^{1} \mathrm{H}\right\}$ NMR $\left(67.8 \mathrm{MHz} \mathrm{CDCl}_{3}\right) \delta 144.7,128.4,127.1,126.8,42.7,42.4,33.8,33.2,26.0,25.8,23.1 \mathrm{IR}$ (neat, $\mathrm{NaCl}$ cell, $v_{\max }, \mathrm{cm}^{-1}$ ) $2927(\mathrm{C}-\mathrm{H}), 2852(\mathrm{C}-\mathrm{H}), 1601(\mathrm{C}=\mathrm{C}), 1491(\mathrm{C}=\mathrm{C}), 1448(\mathrm{C}-\mathrm{H})$; Anal. Calcd for $\mathrm{C}_{14} \mathrm{H}_{20} \mathrm{~S}$ (220.37): C, 76.30; $H, 9.15$. Found: $C, 76.50 ; H, 9.17$.

1-Benzylthio-1-phenylethane (2d). The title compound was obtained as a colorless oil (53.4 mg, 78\%). ${ }^{1} \mathrm{H} \mathrm{NMR}$ $\left(270 \mathrm{MHz}, \mathrm{CDCl}_{3}\right) \delta 7.33-7.18(\mathrm{~m}, 10 \mathrm{H}, \mathrm{Ar}-\mathrm{H}), 3.80(\mathrm{q}, J=7.0 \mathrm{~Hz}, 1 \mathrm{H}, \mathrm{CH}), 3.48(\mathrm{dd}, J=29.0$ and $13.5 \mathrm{~Hz}, 2 \mathrm{H}$, $\left.\mathrm{CH}_{2}\right), 1.53\left(\mathrm{~d}, J=7.0 \mathrm{~Hz}, 3 \mathrm{H}, \mathrm{CH}_{3}\right) ;{ }^{13} \mathrm{C}\left\{{ }^{1} \mathrm{H}\right\} \mathrm{NMR}\left(67.8 \mathrm{MHz}, \mathrm{CDCl}_{3}\right) \delta 143.8,138.4,128.9,128.5,128.4,127.4$, 127.0, 126.8, 43.5, 35.7, 25.5; IR (neat, $\mathrm{NaCl}$ cell, $v_{\max } \mathrm{cm}^{-1}$ ) 3027 (C-H), 2966 (C-H), 1601 (C=C), 1492 (C=C), 1452 (C-H), 1222 (S C-H); Anal. Calcd for $\mathrm{C}_{16} \mathrm{H}_{16} \mathrm{~S}$ (228.35): C, 79.95; H 6.71. Found: C, 79.99; H, 6.82.

2-(1-Butylthio)-2-phenylpropane (2f). The title compound was obtained as a colorless oil $(56.5 \mathrm{mg}, 90 \%) .{ }^{1} \mathrm{H}$ NMR $\left(270 \mathrm{MHz}, \mathrm{CDCl}_{3}\right) \delta 7.55-7.52(\mathrm{~m}, 2 \mathrm{H}, \mathrm{Ar}-\mathrm{H}), 7.34-7.17(\mathrm{~m}, 3 \mathrm{H}, \mathrm{Ar}-\mathrm{H}), 2.21\left(\mathrm{t}, J=7.1 \mathrm{~Hz}, 2 \mathrm{H}, \mathrm{CH}_{2}\right), 1.70(\mathrm{~s}$, $\left.6 \mathrm{H}, \mathrm{CH}_{3}\right), 1.39-1.22\left(\mathrm{~m}, 4 \mathrm{H}, \mathrm{CH}_{2}\right), 0.79\left(\mathrm{t}, J=7.1 \mathrm{~Hz}, 3 \mathrm{H}, \mathrm{CH}_{3}\right) ;{ }^{13} \mathrm{C}\left\{{ }^{1} \mathrm{H}\right\} \mathrm{NMR}\left(67.8 \mathrm{MHz}, \mathrm{CDCl}_{3}\right) \delta 146.8,128.0$, 126.4, 126.3, 47.3, 31.2, 30.3, 29.1, 22.1, 13.6; IR (neat, $\mathrm{NaCl}$ cell, $v_{\max }, \mathrm{cm}^{-1}$ ) 2959 (C-H), 2871 (C-H), 1600 $(C=C), 1493(C=C), 1446(C-H), 1381(C-H), 1364(C-H)$; Anal. Calcd for $\mathrm{C}_{13} \mathrm{H}_{20} \mathrm{~S}$ (208.36): C, 74.94; H, 9.68. Found: $\mathrm{C}, 74.66 ; \mathrm{H} 9.74$.

1-(1-Butylthio)-1-(4-tolyl)ethane (2g). The title compound was obtained as a colorless oil $(54.8 \mathrm{mg}, 88 \%) .{ }^{1} \mathrm{H}$ $\operatorname{NMR}\left(270 \mathrm{MHz}_{\mathrm{CDCl}}\right) \delta 7.22(\mathrm{~d}, J=8.2 \mathrm{~Hz}, 2 \mathrm{H}, \mathrm{Ar}-\mathrm{H}), 7.11(\mathrm{~d}, J=8.2 \mathrm{~Hz}, 2 \mathrm{H}, \mathrm{Ar}-\mathrm{H}), 3.91(\mathrm{q}, J=7.0 \mathrm{~Hz}, 1 \mathrm{H}, \mathrm{CH})$, 2.34-2.24 (m, 5H, CH ${ }^{13} \mathrm{C}\left\{{ }^{1} \mathrm{H}\right\} \operatorname{NMR}\left(67.8 \mathrm{MHz}, \mathrm{CDCl}_{3}\right) \delta 141.2,136.5,129.1,127.1,43.7,31.5,30.9,22.7,22.0,21.0,13.6$; IR (neat, $\mathrm{NaCl}$ cell, $v_{\max }, \mathrm{cm}^{-1}$ ) 2925 (C-H), 2870 (C-H), 1512 (C=C), 1448 (C-H), 1372 (C-H), 1219 (SC-H); Anal. Calcd for $\mathrm{C}_{13} \mathrm{H}_{20} \mathrm{~S}$ (208.36): C, 79.94; $\mathrm{H}, 9.68$. Found: $\mathrm{C}, 74.84 ; \mathrm{H}, 9.62$.

1-(1-Butylthio)-1-(4-methoxyphenyl)ethane (2h). The title compound was obtained as a colorless oil (50.5 mg, 75\%). ${ }^{1} \mathrm{H}$ NMR $\left(270 \mathrm{MHz}, \mathrm{CDCl}_{3}\right) \delta 7.25(\mathrm{~d}, J=8.5 \mathrm{~Hz}, 2 \mathrm{H}, \mathrm{Ar}-\mathrm{H}), 6.85$ (d, J=8.5 Hz, 2H, Ar-H), $3.92(\mathrm{q}, J=6.9 \mathrm{~Hz}$, $1 \mathrm{H}, \mathrm{CH}), 3.79\left(\mathrm{~s}, 3 \mathrm{H}, \mathrm{OCH}_{3}\right), 2.35-2.26\left(\mathrm{~m}, 2 \mathrm{H}, \mathrm{CH}_{2}\right), 1.53\left(\mathrm{~d}, J=6.9 \mathrm{~Hz}, 3 \mathrm{H}, \mathrm{CH}_{3}\right), 1.59-1.29\left(\mathrm{~m}, 4 \mathrm{H}, \mathrm{CH}_{2}\right), 0.85$ $\left(\mathrm{t}, J=7.2 \mathrm{~Hz}, 3 \mathrm{H}, \mathrm{CH}_{3}\right) ;{ }^{13} \mathrm{C}\left\{{ }^{1} \mathrm{H}\right\} \mathrm{NMR}\left(67.8 \mathrm{MHz}, \mathrm{CDCl}_{3}\right) \delta 158.4,136.2,128.2,113.7,55.2,43.3,31.5,30.9,22.7$, 22.0, 13.6; IR (neat, $\mathrm{NaCl}$ cell, $v_{\max } \mathrm{cm}^{-1}$ ) 2958 (C-H), 2871 (C-H), 1611 (C=C), 1511 (C=C), 1464 (C-H), 1247 (SC$\mathrm{H})$; Anal. Calcd for $\mathrm{C}_{13} \mathrm{H}_{20} \mathrm{OS}$ (224.36): C, 69.59; $\mathrm{H}, 8.99$. Found: $\mathrm{C}, 69.77 ; \mathrm{H}, 8.96$.

1-(4-Acetoxyphenyl)-1-(1-Butylthio)ethane (2i). The title compound was obtained as a colorless oil (46.7 mg, 62\%). ${ }^{1} \mathrm{H}$ NMR $\left(270 \mathrm{MHz}, \mathrm{CDCl}_{3}\right) \delta 7.35(\mathrm{~d}, J=8.2 \mathrm{~Hz}, 2 \mathrm{H}, \mathrm{Ar}-\mathrm{H}), 7.03(\mathrm{~d}, J=8.2 \mathrm{~Hz}, 2 \mathrm{H}, \mathrm{Ar}-\mathrm{H}), 3.94(\mathrm{q}, J=7.0 \mathrm{~Hz}$, $1 \mathrm{H}, \mathrm{CH}), 2.34-2.29\left(\mathrm{~m}, 2 \mathrm{H}, \mathrm{CH}_{2}\right), 2.29\left(\mathrm{~s}, 3 \mathrm{H}, \mathrm{COCH}_{3}\right), 1.54\left(\mathrm{~d}, J=7.0 \mathrm{~Hz}, 3 \mathrm{H}, \mathrm{CH}_{3}\right), 1.58-1.26\left(\mathrm{~m}, 4 \mathrm{H}, \mathrm{CH}_{2}\right), 0.85$

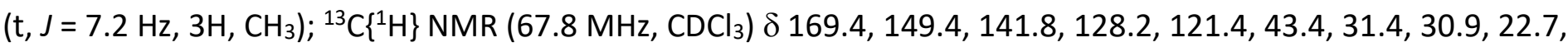
22.0, 21.1, 13.6; IR (neat, $\mathrm{NaCl}$ cell, $v_{\max }, \mathrm{cm}^{-1}$ ) 2960 (C-H), 2928 (C-H), 1767 (C=O), 1505 (C=C), 1369 (C-H); Anal. Calcd for $\mathrm{C}_{14} \mathrm{H}_{20} \mathrm{OS}$ (252.37): C, 66.63; $\mathrm{H}, 7.99$. Found: $\mathrm{C}, 66.61 ; \mathrm{H}, 7.97$.

1-(1-Butylthio)-1-(4-fuluorobenzene)ethane (2j). The title compound was obtained as a colorless oil (50.5 mg, 79\%). ${ }^{1} \mathrm{H}$ NMR (270 MHz, CDCl 3 ) $\delta 7.33-7.26(\mathrm{~m}, 2 \mathrm{H}, \mathrm{Ar}-\mathrm{H}), 7.03-6.96(\mathrm{~m}, 2 \mathrm{H}, \mathrm{Ar}-\mathrm{H}), 3.93(\mathrm{q}, J=7.1 \mathrm{~Hz}, 1 \mathrm{H}, \mathrm{CH})$, 2.35-2.34 (m, 2H, CH 2$), 1.55-1.26\left(\mathrm{~m}, 4 \mathrm{H}, \mathrm{CH}_{2}\right), 1.54\left(\mathrm{~d}, J=6.9 \mathrm{~Hz}, 3 \mathrm{H}, \mathrm{CH}_{3}\right), 0.85\left(\mathrm{t}, J=7.1 \mathrm{~Hz}, 3 \mathrm{H}, \mathrm{CH}_{3}\right)$; ${ }^{13} \mathrm{C}\left\{{ }^{1} \mathrm{H}\right\} \operatorname{NMR}\left(67.8 \mathrm{MHz}, \mathrm{CDCl}_{3}\right) \delta=161.7\left(\mathrm{~d},{ }^{1} J_{C-F}=244.8 \mathrm{~Hz}\right), 139.7\left(\mathrm{~d},{ }^{4} J_{C-F}=3.4 \mathrm{~Hz}\right), 128.7\left(\mathrm{~d},{ }^{3} J_{C-F}=8.8 \mathrm{~Hz}\right)$, $115.2\left(d,{ }^{2} J_{C-F}=21.7 \mathrm{~Hz}\right), 43.3,31.4,30.9,22.7(\mathrm{~d}, J=0.7 \mathrm{~Hz}), 22.0,13.6$; IR (neat, $\mathrm{NaCl}$ cell, $\left.v_{\max }, \mathrm{cm}^{-1}\right) 2960(\mathrm{C}-$ H), 2872 (C-H), 1603 (C=C), 1508 (C=C), 1452 (C-H), 1223 (SC-H); Anal. Calcd for $\mathrm{C}_{12} \mathrm{H}_{17} \mathrm{FS}$ (212.33): C, 67.88; H, 8.07. Found: $\mathrm{C}, 68.15 ; \mathrm{H}, 8.25$ 
1-(1-Butylthio)-1-(4-chlorophenyl)ethane (2k). The title compound was obtained as a colorless oil (50.6 mg, 74\%). ${ }^{1} \mathrm{H}$ NMR (270 MHz, $\left.\mathrm{CDCl}_{3}\right) \delta 7.27(\mathrm{~s}, 4 \mathrm{H}, \mathrm{Ar}-\mathrm{H}), 3.91$ (q, J = $\left.7.1 \mathrm{~Hz}, 1 \mathrm{H}, \mathrm{CH}\right), 2.35-2.21\left(\mathrm{~m}, 2 \mathrm{H}, \mathrm{CH}_{2}\right), 1.56-$ $1.25\left(\mathrm{~m}, 4 \mathrm{H}, \mathrm{CH}_{2}\right), 1.55\left(\mathrm{~d}, J=6.9 \mathrm{~Hz}, 3 \mathrm{H}, \mathrm{CH}_{3}\right), 0.85\left(\mathrm{t}, J=7.2 \mathrm{~Hz}, 3 \mathrm{H}, \mathrm{CH}_{3}\right) ;{ }^{13} \mathrm{C}\left\{{ }^{1} \mathrm{H}\right\} \mathrm{NMR}\left(67.8 \mathrm{MHz}^{\mathrm{CDCl}} \mathrm{CD}_{3} \delta\right.$ 142.8, 132.5, 128.6, 128.5, 43.4, 31.4, 30.9, 22.6, 22.0, 13.6; IR (neat, NaCl cell, $v_{\text {max }} \mathrm{cm}^{-1}$ ) 2959 (C-H), 2871 (CH), 1491 (C-H), 1465 (C-H), 1215 (SC-H), 1092 (C-H); Anal. Calcd for $\mathrm{C}_{12} \mathrm{H}_{17} \mathrm{ClS}$ (228.78): C, 63.00; H, 7.49. Found: C, $63.11 ; \mathrm{H} 7.62$.

1-(1-Butylthio)-1-(4-bromophenyl)ethane (2I). The title compound was obtained as a colorless oil (66.3 $\mathrm{mg}$, 81\%). ${ }^{1} \mathrm{H}$ NMR $\left(270 \mathrm{MHz}, \mathrm{CDCl}_{3}\right) \delta 7.45-7.41(\mathrm{~m}, 2 \mathrm{H}, \mathrm{Ar}-\mathrm{H}), 7.24-7.20(\mathrm{~m}, 2 \mathrm{H}), 3.90(\mathrm{q}, J=7.0 \mathrm{~Hz}, 1 \mathrm{H}, \mathrm{CH})$, 2.33-2.25 (m, 2H, CH$), 1.56-1.28\left(\mathrm{~m}, 4 \mathrm{H}, \mathrm{CH}_{2}\right), 1.52\left(\mathrm{dd}, J=6.9\right.$ and $\left.0.7 \mathrm{~Hz}, 3 \mathrm{H}, \mathrm{CH}_{3}\right), 0.88(\mathrm{t}, J=7.4 \mathrm{~Hz}, 3 \mathrm{H}$, $\left.\mathrm{CH}_{3}\right) ;{ }^{13} \mathrm{C}\left\{{ }^{1} \mathrm{H}\right\} \operatorname{NMR}\left(67.8 \mathrm{MHz}, \mathrm{CDCl}_{3}\right) \delta 143.4,131.5,128.9,120.5,43.4,31.3,30.9,22.5,22.0,13.6$; IR (neat, $\mathrm{NaCl}$ cell, $v_{\max } \mathrm{cm}^{-1}$ ) 2959 (C-H), 2870 (C-H), 1487 (C-H), 1450 (C-H), 1213 (SC-H); Anal. Calcd for $\mathrm{C}_{12} \mathrm{H}_{17} \mathrm{BrS}$ (273.23): C, 52.75; H, 6.27. Found: $C, 52.68 ; H, 6.21$.

1-(1-Butylthio)-1-(2-bromophenyl)ethane (2m). The title compound was obtained as a colorless oil (56.2 $\mathrm{mg}$, 69\%). ${ }^{1} \mathrm{H}$ NMR $\left(270 \mathrm{MHz}_{\mathrm{CDCl}}\right.$ ) $\delta 7.62$ (d, $\left.J=7.9 \mathrm{~Hz}, 1 \mathrm{H}, \mathrm{Ar}-\mathrm{H}\right), 7.50$ (d, J=8.2 Hz, 1H, Ar-H), 7.31 (dd, $J=7.9$ and $8.2 \mathrm{~Hz}, 1 \mathrm{H}, \mathrm{Ar}-\mathrm{H}), 7.05(\mathrm{~d}, J=7.9$ and $8.2 \mathrm{~Hz}, 1 \mathrm{H}, \mathrm{Ar}-\mathrm{H}), 4.53(\mathrm{q}, J=7.0 \mathrm{~Hz}, 1 \mathrm{H}, \mathrm{CH}), 2.42-2.30\left(\mathrm{~m}, 2 \mathrm{H}, \mathrm{CH}_{2}\right)$, $1.51\left(\mathrm{~d}, J=6.9 \mathrm{~Hz}, 3 \mathrm{H}, \mathrm{CH}_{3}\right), 1.56-1.30\left(\mathrm{~m}, 4 \mathrm{H}, \mathrm{CH}_{2}\right), 0.85\left(\mathrm{t}, J=7.2 \mathrm{~Hz}, 3 \mathrm{H}, \mathrm{CH}_{3}\right) ;{ }^{13} \mathrm{C}\left\{{ }^{1} \mathrm{H}\right\} \mathrm{NMR}(67.8 \mathrm{MHz}$, $\left.\mathrm{CDCl}_{3}\right) \delta 143.3,132.5,128.6,128.2,127.9,123.8,42.4,31.5,31.0,22.2,21.9,13.5$; IR (neat, NaCl cell, $v_{\text {max }}, \mathrm{cm}^{-}$ 1) 2958 (C-H), 2870 (C-H), 1565 (C=C), 1466 (C-H), 1438 (C-H), 1373 (C-H), 1221 (SC-H); Anal. Calcd for $\mathrm{C}_{12} \mathrm{H}_{17} \mathrm{BrS}$ (273.23): C, 52.75; H 6.27. Found: $C, 52.93 ; \mathrm{H}, 6.32$.

1-(1-Butylthio)indane (2n). The title compound was obtained as a colorless oil $(45.8 \mathrm{mg}, 74 \%) .{ }^{1} \mathrm{H}$ NMR (270 $\left.\mathrm{MHz}, \mathrm{CDCl}_{3}\right) \delta$ 7.36-7.33 (m, 1H, Ar-H), 7.24-7.16 (m, 3H, Ar-H), 4.34-4.29 (m, 1H, CH), 3.10-2.93 $\left(\mathrm{m}, 1 \mathrm{H}, \mathrm{CH}_{2}\right)$, 2.91-2.80 (m, $\left.1 \mathrm{H}, \mathrm{CH}_{2}\right), 2.59-2.45\left(\mathrm{~m}, 3 \mathrm{H}, \mathrm{CH}_{2}\right), 2.17-2.09\left(\mathrm{~m}, 1 \mathrm{H}, \mathrm{CH}_{2}\right), 1.65-1.54\left(\mathrm{~m}, 2 \mathrm{H}, \mathrm{CH}_{2}\right), 1.48-1.34(\mathrm{~m}$, $\left.2 \mathrm{H}, \mathrm{CH}_{2}\right), 0.91\left(\mathrm{t}, J=7.2 \mathrm{~Hz}, 3 \mathrm{H}, \mathrm{CH}_{3}\right) ;{ }^{13} \mathrm{C}\left\{{ }^{1} \mathrm{H}\right\} \mathrm{NMR}\left(67.8 \mathrm{MHz}, \mathrm{CDCl}_{3}\right) \delta 143.6,143.5,127.3,126.4,124.6,48.8$, 34.1, 31.8, 31.0, 30.6, 22.1, 13.7; IR (neat, NaCl cell, $v_{\max } \mathrm{cm}^{-1}$ ) 2959 (C-H), 2929 (C-H), 1459 (C-H), 1378 (C-H); Anal. Calcd for $\mathrm{C}_{13} \mathrm{H}_{18} \mathrm{~S}$ (206.35): C, 75.67; H, 8.79. Found: $\mathrm{C}, 75.92 ; \mathrm{H} 8.86$.

1,2,3,4-Tetrahydro-1-(1-Butylthio)naphthaene (20). The title compound was obtained as a colorless oil (52.8 $\mathrm{mg}, 80 \%) .{ }^{1} \mathrm{H}$ NMR (270 MHz, $\left.\mathrm{CDCl}_{3}\right) \delta 7.40-7.36(\mathrm{~m}, 1 \mathrm{H}, \mathrm{Ar}-\mathrm{H}), 7.13-7.03(\mathrm{~m}, 3 \mathrm{H}, \mathrm{Ar}-\mathrm{H}), 4.09(\mathrm{t}, J=4.1 \mathrm{~Hz}, 1 \mathrm{H}$, $\mathrm{CH}), 2.82-2.73\left(\mathrm{~m}, 2 \mathrm{H}, \mathrm{CH}_{2}\right), 2.67-2.49\left(\mathrm{~m}, 2 \mathrm{H}, \mathrm{CH}_{2}\right), 2.16-2.05\left(\mathrm{~m}, 3 \mathrm{H}, \mathrm{CH}_{2}\right), 1.80-1.74\left(\mathrm{~m}, 1 \mathrm{H}, \mathrm{CH}_{2}\right), 1.64-$ $1.54\left(\mathrm{~m}, 2 \mathrm{H}, \mathrm{CH}_{2}\right), 1.47-1.39\left(\mathrm{~m}, 2 \mathrm{H}, \mathrm{CH}_{2}\right), 0.92\left(\mathrm{t}, J=7.1 \mathrm{~Hz}, 3 \mathrm{H}, \mathrm{CH}_{3}\right) ;{ }^{13} \mathrm{C}\left\{{ }^{1} \mathrm{H}\right\} \mathrm{NMR}\left(67.8 \mathrm{MHz}, \mathrm{CDCl}_{3}\right) \delta 137.3$, 136.8, 130.2, 129.1, 126.6, 125.6, 43.8, 31.7, 31.3, 29.2, 29.1, 22.2, 19.1, 13.7; IR (neat, $\mathrm{NaCl}$ cell, $v_{\max }, \mathrm{cm}^{-1}$ ) 2931 (C-H), 2870 (C-H), 1693 (C=C), 1487 (C-H), 1452 (C-H), 1269 (SC-H); Anal. Calcd for C ${ }_{14} \mathrm{H}_{20} \mathrm{~S}$ (220.37): C, 76.30; $H, 9.15$. Found: $C, 76.27 ; H, 9.11$.

1-(1-Butylthio)-1-methylcyclohexane (2p). The title compound was obtained as a colorless oil (48.1 mg, $86 \%)$. ${ }^{1} \mathrm{H}$ NMR $\left(270 \mathrm{MHz}, \mathrm{CDCl}_{3}\right) \delta 2.44(\mathrm{t}, J=7.2 \mathrm{~Hz}, 2 \mathrm{H}, \mathrm{Ar}-\mathrm{H}), 1.69-1.65\left(\mathrm{~m}, 2 \mathrm{H}, \mathrm{CH}_{2}\right), 1.59-137\left(\mathrm{~m}, 12 \mathrm{H}, \mathrm{CH}_{2}\right), 1.31$ $\left(\mathrm{s}, 3 \mathrm{H}, \mathrm{CH}_{3}\right), 0.91\left(\mathrm{t}, J=7.2 \mathrm{~Hz}, 3 \mathrm{H}, \mathrm{CH}_{3}\right) ;{ }^{13} \mathrm{C}\left\{{ }^{1} \mathrm{H}\right\} \mathrm{NMR}\left(67.8 \mathrm{MHz}, \mathrm{CDCl}_{3}\right) \delta 45.9,38.3,31.9,28.8,28.7,26.5$, 25.9, 22.4, 13.7; IR (neat, $\mathrm{NaCl}$ cell, $v_{\max }, \mathrm{cm}^{-1}$ ) 2929 (C-H), 2858 (C-H), 1446 (C-H), 1375 (C-H), 1272 (SC-H); Anal. Calcd for $\mathrm{C}_{11} \mathrm{H}_{22} \mathrm{~S}$ (186.36): C, $70.90 ; \mathrm{H}, 11.90$. Found: $\mathrm{C}, 71.11 ; \mathrm{H}, 11.64$.

1-[(1-Butylthio)ethyl]-2-pyrrolidinone (2q). The title compound was obtained as a colorless oil (48.7 mg, $81 \%)$. ${ }^{1} \mathrm{H}$ NMR $\left(270 \mathrm{MHz}, \mathrm{CDCl}_{3}\right) \delta 5.54(\mathrm{q}, J=7.0 \mathrm{~Hz}, 1 \mathrm{H}, \mathrm{CH}), 3.66-3.57(\mathrm{~m}, 1 \mathrm{H}, \mathrm{CH}), 3.35-3.26(\mathrm{~m}, 1 \mathrm{H}, \mathrm{CH}), 2.54-$ $2.29\left(\mathrm{~m}, 4 \mathrm{H}, \mathrm{CH}_{2}\right), 2.09-1.98\left(\mathrm{~m}, 2 \mathrm{H}, \mathrm{CH}_{2}\right), 1.63-1.32\left(\mathrm{~m}, 4 \mathrm{H}, \mathrm{CH}_{2}\right), 1.39\left(\mathrm{~d}, J=6.9 \mathrm{~Hz}, \mathrm{CH}_{3}\right), 0.89(\mathrm{t}, J=7.2 \mathrm{~Hz}$, $\left.3 \mathrm{H}, \mathrm{CH}_{3}\right) ;{ }^{13} \mathrm{C}\left\{{ }^{1} \mathrm{H}\right\} \mathrm{NMR}\left(67.8 \mathrm{MHz}, \mathrm{CDCl}_{3}\right) \delta 174.6,51.6,40.9,31.6,31.5,30.5,21.9,19.2,17.8,13.5$; IR (neat, $\mathrm{NaCl}$ cell, $\nu_{\max }, \mathrm{cm}^{-1}$ ) 2957 (C-H), 2873 (C-H), 1687 (C=O), 1459 (C-H), 1419 (C-H), 1267 (SC-H); Anal. Calcd for $\mathrm{C}_{10} \mathrm{H}_{19} \operatorname{NOS}$ (201.33): C, 59.66; H 9.51. Found: C, 59.31; H, 9.59. 
Typical procedure for zinc-catalyzed hydrothiolation of alkenes: Synthesis of 1-(1-Butylthio)-2-phenylethane (3a) (Table 3, entry 1)

To a mixture of styrene (31.2 mg, $0.3 \mathrm{mmol}), 1$-butanethiol $(29.8 \mathrm{mg}, 0.33 \mathrm{mmol})$, in $\mathrm{PhCH}_{3}(0.3 \mathrm{~mL}), \mathrm{Zn}(\mathrm{OAc})_{2}$ $\left(5.5 \mathrm{mg}, 0.03 \mathrm{mmol}\right.$ ) was added, and the mixture was stirred at $100{ }^{\circ} \mathrm{C}$ for $36 \mathrm{~h}$ in the presence of air in $15 \mathrm{~mL}$ glass test tube with plastic screw cap. After the residue was dissolved in $\mathrm{Et}_{2} \mathrm{O}$, the solution was washed with $\mathrm{H}_{2} \mathrm{O}$ and saturated aq $\mathrm{NaCl}$ and dried over anhydrous $\mathrm{MgSO}_{4}$. Chromatography on silica gel (hexane) gave 1-(1butylthio)-2-phenylethane 3a (50.9 mg, 87\%): Colorless oil; ${ }^{1} \mathrm{H} \mathrm{NMR}\left(270 \mathrm{MHz}, \mathrm{CDCl}_{3}\right) \delta 7.32-7.19(\mathrm{~m}, 5 \mathrm{H}, \mathrm{Ar}-$ $\mathrm{H}), 2.92-2.85\left(\mathrm{~m}, 2 \mathrm{H}, \mathrm{CH}_{2}\right), 2.80-2.73\left(\mathrm{~m}, 2 \mathrm{H}, \mathrm{CH}_{2}\right), 2.53\left(\mathrm{t}, J=7.4 \mathrm{~Hz}, 2 \mathrm{H}, \mathrm{CH}_{2}\right), 1.63-1.52\left(\mathrm{~m}, 2 \mathrm{H}, \mathrm{CH}_{2}\right), 1.47-$ $1.33\left(\mathrm{~m}, 2 \mathrm{H}, \mathrm{CH}_{2}\right), 0.91\left(\mathrm{t}, J=7.4 \mathrm{~Hz}, 3 \mathrm{H}, \mathrm{CH}_{3}\right) ;{ }^{13} \mathrm{C}\left\{{ }^{1} \mathrm{H}\right\} \mathrm{NMR}\left(67.8 \mathrm{MHz}, \mathrm{CDCl}_{3}\right) \delta 140.7,128.4,128.4,126.3,36.4$, 33.6, 32.0, 31.7, 22.0, 13.7; IR (neat, $\mathrm{NaCl}$ cell, $v_{\max }, \mathrm{cm}^{-1}$ ) 2955 (C-H), 2871 (C-H), 1604 (C=C), 1496 (C-H), 1453 (C-H), 1273 (SC-H); Anal. Calcd for $\mathrm{C}_{12} \mathrm{H}_{18} \mathrm{~S}$ (208.36): C, 74.17; H, 9.34. Found: C, 74.30; H, 9.42.

1-(1-Octylthio)-2-phenylethane (3b). The title compound was obtained as a colorless oil $(60.8 \mathrm{mg}, 81 \%) .{ }^{1} \mathrm{H}$ NMR (270 MHz, CDCl $)_{3} \delta 7.32-7.19(\mathrm{~m}, 5 \mathrm{H}, \mathrm{Ar}-\mathrm{H}), 2.91-2.85\left(\mathrm{~m}, 2 \mathrm{H}, \mathrm{CH}_{2}\right), 2.80-2.73\left(\mathrm{~m}, 2 \mathrm{H}, \mathrm{CH}_{2}\right), 2.53(\mathrm{t}, J=$ $\left.7.4 \mathrm{~Hz}, 2 \mathrm{H}, \mathrm{CH}_{2}\right), 1.63-1.52\left(\mathrm{~m}, 2 \mathrm{H}, \mathrm{CH}_{2}\right), 1.40-1.27\left(\mathrm{~m}, 10 \mathrm{H}, \mathrm{CH}_{2}\right), 0.88\left(\mathrm{t}, J=6.6 \mathrm{~Hz}, 3 \mathrm{H}, \mathrm{CH}_{3}\right) ;{ }^{13} \mathrm{C}\left\{{ }^{1} \mathrm{H}\right\} \mathrm{NMR}$ $\left(67.8 \mathrm{MHz}, \mathrm{CDCl}_{3}\right) \delta 140.7,128.4,128.4,126.3,36.4,33.6,32.3,31.8,29.6,29.2,29.1,28.9,22.6,14.1$; IR (neat, $\mathrm{NaCl}$ cell, $V_{\max }, \mathrm{cm}^{-1}$ ) 2925 (C-H), $2854(\mathrm{C}-\mathrm{H}), 1604$ (C=C), 1496 (C-H), 1454 (C-H); Anal. Calcd for C ${ }_{16} \mathrm{H}_{26} \mathrm{~S}$ (250.44): C, 76.73; $\mathrm{H}, 10.46$. Found: $\mathrm{C}, 76.80 ; \mathrm{H}, 10.20$.

1-(1-Cyclohexylthio)-2-phenylethane (3c). The title compound was obtained as a colorless oil (52.4 mg, $79 \%)$. ${ }^{1} \mathrm{H}$ NMR $\left(270 \mathrm{MHz}, \mathrm{CDCl}_{3}\right) \delta 7.32-7.18(\mathrm{~m}, 5 \mathrm{H}, \mathrm{Ar}-\mathrm{H}), 2.91-2.75\left(\mathrm{~m}, 4 \mathrm{H}, \mathrm{CH}_{2}\right), 2.65-2.61(\mathrm{~m}, 1 \mathrm{H}, \mathrm{CH}), 1.99-1.95$ $\left(\mathrm{m}, 2 \mathrm{H}, \mathrm{CH}_{2}\right), 1.77-1.75\left(\mathrm{~m}, 2 \mathrm{H}, \mathrm{CH}_{2}\right), 1.65-1.56(\mathrm{~m}, 1 \mathrm{H}), 1.31-1.23\left(\mathrm{~m}, 5 \mathrm{H}, \mathrm{CH}_{2}\right) ;{ }^{13} \mathrm{C}\left\{{ }^{1} \mathrm{H}\right\} \mathrm{NMR}(67.8 \mathrm{MHz}$, $\left.\mathrm{CDCl}_{3}\right) \delta 140.8,128.4,126.3,43.7,36.7,33.7,31.7,26.1,25.8 ; \mathrm{IR}\left(\mathrm{CHCl}_{3}, \mathrm{NaCl}\right.$ cell, $\left.v_{\max }, \mathrm{cm}^{-1}\right) 2932$ (C-H), 2854 (C-H), $1464(\mathrm{C}-\mathrm{H}), 1449$ (C-H), 1264 (SC-H); Anal. Calcd for $\mathrm{C}_{14} \mathrm{H}_{20} \mathrm{~S}$ (220.37): C, 76.30 ; H, 9.15. Found: C, 76.37; H, 9.15 .

1-(1-Benzylthio)-2-phenylethane (3d). The title compound was obtained as a colorless oil $(53.4 \mathrm{mg}, 78 \%) .{ }^{1} \mathrm{H}$ NMR $\left(270 \mathrm{MHz}_{2} \mathrm{CDCl}_{3}\right) \delta 7.32-7.13(\mathrm{~m}, 10 \mathrm{H}, \mathrm{Ar}-\mathrm{H}), 3.71\left(\mathrm{~s}, 2 \mathrm{H}, \mathrm{CH}_{2}\right), 2.86-2.80\left(\mathrm{~m}, 2 \mathrm{H}, \mathrm{CH}_{2}\right), 2.68-2.62(\mathrm{~m}, 2 \mathrm{H}$, $\left.\mathrm{CH}_{2}\right) ;{ }^{13} \mathrm{C}\left\{{ }^{1} \mathrm{H}\right\} \operatorname{NMR}\left(67.8 \mathrm{MHz}, \mathrm{CDCl}_{3}\right) \delta 140.5,138.4,128.9,128.5,128.4,127.0,126.3,36.4,36.0,32.7$; IR (neat, $\mathrm{NaCl}$ cell, $v_{\max }, \mathrm{cm}^{-1}$ ) 3061 (C-H), 3026 (C-H), 2915 (C-H), 1602 (C=C), 1494 (C-H), 1453 (C-H); Anal. Calcd for $\mathrm{C}_{15} \mathrm{H}_{16} \mathrm{~S}$ (228.35): C, 78.90; H, 7.06. Found: C, 78.91; $\mathrm{H}, 6.95$.

1-(1-Buthylthio)- 2-phenylpropane (3e). The title compound was obtained as a colorless oil $(41.9 \mathrm{mg}, 67 \%) .{ }^{1} \mathrm{H}$ NMR $\left(270 \mathrm{MHz}, \mathrm{CDCl}_{3}\right) \delta 7.34-7.28(\mathrm{~m}, 2 \mathrm{H}, \mathrm{Ar}-\mathrm{H}), 7.25-7.18(\mathrm{~m}, 3 \mathrm{H}, \mathrm{Ar}-\mathrm{H}), 2.98-2.90(\mathrm{~m}, 1 \mathrm{H}, \mathrm{CH}), 2.83-2.71$ $\left(\mathrm{m}, 1 \mathrm{H}, \mathrm{CH}_{2}\right), 2.67-2.64\left(\mathrm{~m}, 1 \mathrm{H}, \mathrm{CH}_{2}\right), 2.44\left(\mathrm{t}, J=7.2 \mathrm{~Hz}, 2 \mathrm{H}, \mathrm{CH}_{2}\right), 1.58-1.47\left(\mathrm{~m}, 2 \mathrm{H}, \mathrm{CH}_{2}\right), 1.43-1.30(\mathrm{~m}, 5 \mathrm{H}$, $\left.\mathrm{CH}_{2}\right), 0.89\left(\mathrm{~d}, J=7.2 \mathrm{~Hz}, 3 \mathrm{H}, \mathrm{CH}_{3}\right) ;{ }^{13} \mathrm{C}\left\{{ }^{1} \mathrm{H}\right\} \mathrm{NMR}\left(67.8 \mathrm{MHz}, \mathrm{CDCl}_{3}\right) \delta 146.0,128.4,126.9,126.4,40.8,40.2,32.4$, 31.7, 22.0, 21.0, 13.7; IR (neat, NaCl cell, $v_{\max }, \mathrm{cm}^{-1}$ ) 2859 (C-H), 1602 (C=C), 1493 (C-H), 1452 (C-H), 1375 (C-H); Anal. Calcd for $\mathrm{C}_{13} \mathrm{H}_{20} \mathrm{~S}$ (208.36): C, 74.94; H, 9.68. Found: $\mathrm{C}, 74.62 ; \mathrm{H}, 9.61$.

1-(1-Buthylthio)-2-(4-tolyl)ethane (3f). The title compound was obtained as a colorless oil (44.3 $\mathrm{mg}, 81 \%) .{ }^{1} \mathrm{H}$ NMR (270 MHz, CDCl $)_{3} \delta$ 7.13-7.07 (m, 4H, Ar-H), 2.88-2.81 (m, 2H, CH $), 2.77-2.71\left(\mathrm{~m}, 2 \mathrm{H}, \mathrm{CH}_{2}\right), 2.53(\mathrm{t}, \mathrm{J}=$ $\left.7.4 \mathrm{~Hz}, 2 \mathrm{H}, \mathrm{CH}_{2}\right), 2.32\left(\mathrm{~s}, 3 \mathrm{H}, \mathrm{CH}_{3}\right), 1.63-1.54\left(\mathrm{~m}, 2 \mathrm{H}, \mathrm{CH}_{2}\right), 1.52-1.33\left(\mathrm{~m}, 2 \mathrm{H}, \mathrm{CH}_{2}\right), 0.91\left(\mathrm{~d}, J=7.3 \mathrm{~Hz}, 3 \mathrm{H}, \mathrm{CH}_{3}\right)$; ${ }^{13} \mathrm{C}\left\{{ }^{1} \mathrm{H}\right\} \operatorname{NMR}\left(67.8 \mathrm{MHz}^{\left.\mathrm{C} C \mathrm{CDl}_{3}\right)} \delta 137.6,135.8,129.1,128.3,35.9,33.8,31.9,31.7,22.0,21.0,13.7 ; \mathrm{IR}\left(\mathrm{CHCl}_{3}\right.\right.$, $\mathrm{NaCl}$ cell, $v_{\max }, \mathrm{cm}^{-1}$ ) 2961 (C-H), 2930 (C-H), 1422 (C-H); Anal. Calcd for $\mathrm{C}_{13} \mathrm{H}_{20} \mathrm{~S}$ (208.36): C, 74.94; H, 9.68. Found: $\mathrm{C}, 74.86 ; \mathrm{H}, 9.81$.

1-(1-Buthylthio)-2-(4-methoxyphenyl)ethane (3g). The title compound was obtained as a colorless oil (43.1 $\mathrm{mg}, 64 \%) .{ }^{1} \mathrm{H}$ NMR $\left(270 \mathrm{MHz}, \mathrm{CDCl}_{3}\right) \delta 7.13(\mathrm{~d}, J=8.9 \mathrm{~Hz}, 2 \mathrm{H}, \mathrm{Ar}-\mathrm{H}), 6.84(\mathrm{~d}, J=8.9 \mathrm{~Hz}, 2 \mathrm{H}, \mathrm{Ar}-\mathrm{H}), 3.78(\mathrm{~s}, 3 \mathrm{H}$, $\left.\mathrm{CH}_{3}\right), 2.86-2.80\left(\mathrm{~m}, 2 \mathrm{H}, \mathrm{CH}_{2}\right), 2.76-2.69\left(\mathrm{~m}, 2 \mathrm{H}, \mathrm{CH}_{2}\right), 2.53\left(\mathrm{t}, J=7.2 \mathrm{~Hz}, 2 \mathrm{H}, \mathrm{CH}_{2}\right), 1.63-1.52\left(\mathrm{~m}, 2 \mathrm{H}, \mathrm{CH}_{2}\right)$, 1.47-1.33 (m, $\left.2 \mathrm{H}, \mathrm{CH}_{2}\right), 0.91\left(\mathrm{~d}, J=7.2 \mathrm{~Hz}, 3 \mathrm{H}, \mathrm{CH}_{3}\right) ;{ }^{13} \mathrm{C}\left\{{ }^{1} \mathrm{H}\right\} \mathrm{NMR}\left(67.8 \mathrm{MHz}, \mathrm{CDCl}_{3}\right) \delta 158.1,132.8,129.4$, 
113.8, 55.2, 35.4, 33.9, 31.9, 31.7, 22.0, 13.7; IR (neat, NaCl cell, $v_{\max }, \mathrm{cm}^{-1}$ ) 2955 (C-H), 2871 (C-H), 1611 (C=C), 1512 (C=C), 1464 (C-H); Anal. Calcd for $\mathrm{C}_{13} \mathrm{H}_{20} \mathrm{OS}$ (224.36): C, 69.59; H, 8.99. Found: C, 69.33; H, 8.89.

1-(1-Buthylthio)-2-(4-fluorophenyl)ethane (3h). The title compound was obtained as a colorless oil $(40.9 \mathrm{mg}$, 64\%). ${ }^{1} \mathrm{H}$ NMR (270 MHz, $\left.\mathrm{CDCl}_{3}\right) \delta$ 7.19-7.14 (m, 2H, Ar-H), 7.01-6.95 (m, 2H, Ar-H), 2.88-2.83 (m, 2H, $\left.\mathrm{CH}_{2}\right)$, 2.77-2.71 (m, 2H, CH $\left.\mathrm{CH}_{2}\right), 2.523\left(\mathrm{t}, \mathrm{J}=7.4 \mathrm{~Hz}, 2 \mathrm{H}, \mathrm{CH}_{2}\right), 1.62-1.54\left(\mathrm{~m}, 2 \mathrm{H}, \mathrm{CH}_{2}\right), 1.51-1.33\left(\mathrm{~m}, 2 \mathrm{H}, \mathrm{CH}_{2}\right), 0.91(\mathrm{~d}, J$ $\left.=7.2 \mathrm{~Hz}, 3 \mathrm{H}, \mathrm{CH}_{3}\right) ;{ }^{13} \mathrm{C}\left\{{ }^{1} \mathrm{H}\right\} \operatorname{NMR}\left(67.8 \mathrm{MHz}_{,} \mathrm{CDCl}_{3}\right) \delta 161.5\left(\mathrm{~d},{ }^{1} J_{C-F}=243.4 \mathrm{~Hz}\right), 136.3\left(\mathrm{~d},{ }^{4} J_{C-F}=3.4 \mathrm{~Hz}\right), 129.8(\mathrm{~d}$, ${ }^{3} J_{C-F}=7.5 \mathrm{~Hz}$ ), $115.2\left(\mathrm{~d},{ }^{2} J_{C-F}=21.0 \mathrm{~Hz}\right.$ ), 35.5, $22.7\left(\mathrm{~d}, J_{C-F}=1.4 \mathrm{~Hz}\right.$ ), 32.0, 31.7, 21.9, 13.7; IR (neat, $\mathrm{NaCl}$ cell, $V_{\max } \mathrm{cm}^{-1}$ ) 2957 (C-H), $2930(\mathrm{C}-\mathrm{H}), 1601(\mathrm{C}=\mathrm{C}), 1510$ (C=C), 1465 (C-H); Anal. Calcd for $\mathrm{C}_{12} \mathrm{H}_{17} \mathrm{FS}$ (212.33): C, 67.88; $\mathrm{H}, 8.07$. Found: $\mathrm{C}, 67.99 ; \mathrm{H}, 8.15$.

1-(1-Buthylthio)-2-(4-bromophenyl)ethane (3i). The title compound was obtained as a colorless oil (58.9 mg, 72\%). ${ }^{1} \mathrm{H}$ NMR $\left(270 \mathrm{MHz}, \mathrm{CDCl}_{3}\right) \delta 7.26(\mathrm{~d}, J=8.2 \mathrm{~Hz}, 2 \mathrm{H}, \mathrm{Ar}-\mathrm{H}), 7.13(\mathrm{~d}, J=8.2 \mathrm{~Hz}, 2 \mathrm{H}, \mathrm{Ar}-\mathrm{H}), 2.88-2.82(\mathrm{~m}, 2 \mathrm{H}$, $\left.\mathrm{CH}_{2}\right), 2.77-2.71\left(\mathrm{~m}, 2 \mathrm{H}, \mathrm{CH}_{2}\right), 2.52\left(\mathrm{t}, J=7.4 \mathrm{~Hz}, 2 \mathrm{H}, \mathrm{CH}_{2}\right), 1.62-1.51\left(\mathrm{~m}, 2 \mathrm{H}, \mathrm{CH}_{2}\right), 1.44-1.36\left(\mathrm{~m}, 2 \mathrm{H}, \mathrm{CH}_{2}\right), 0.91$ $\left(\mathrm{d}, J=7.2 \mathrm{~Hz}, 3 \mathrm{H}, \mathrm{CH}_{3}\right) ;{ }^{13} \mathrm{C}\left\{{ }^{1} \mathrm{H}\right\} \mathrm{NMR}\left(67.8 \mathrm{MHz}, \mathrm{CDCl}_{3}\right) \delta 139.1,129.8,128.5,35.6,33.5,32.0,31.7,22.0,13.7$; IR $\left(\mathrm{CHCl}_{3}, \mathrm{NaCl}\right.$ cell, $\left.v_{\max }, \mathrm{cm}^{-1}\right) 3019(\mathrm{C}-\mathrm{H}), 2961(\mathrm{C}-\mathrm{H}), 1600(\mathrm{C}=\mathrm{C}), 1492(\mathrm{C}-\mathrm{H})$; Anal. Calcd for $\mathrm{C}_{12} \mathrm{H}_{17} \mathrm{~S}(273.23)$ : C, 52.75; H, 6.27. Found: $C, 52.94 ; H, 6.22$.

1-(1-Buthylthio)-3-phenylpropane (3j). The title compound was obtained as a colorless oil (15.7 mg, $25 \%) .{ }^{1} \mathrm{H}$ $\operatorname{NMR}\left(270 \mathrm{MHz}_{\mathrm{CDCl}}\right) \delta$ 7.31-7.26 (m, 2H, Ar-H), 7.20-7.17 (m, 3H, Ar-H), $2.72(\mathrm{t}, \mathrm{J}=7.6 \mathrm{~Hz}, 2 \mathrm{H}, \mathrm{CH}), 2.55-$ $2.48\left(\mathrm{~m}, 4 \mathrm{H}, \mathrm{CH}_{2}\right), 1.96-1.85\left(\mathrm{~m}, 2 \mathrm{H}, \mathrm{CH}_{2}\right), 1.60-1.49\left(\mathrm{~m}, 2 \mathrm{H}, \mathrm{CH}_{2}\right), 1.46-1.33\left(\mathrm{~m}, 2 \mathrm{H}, \mathrm{CH}_{2}\right), 0.91(\mathrm{~d}, \mathrm{~J}=7.2 \mathrm{~Hz}$, $\left.3 \mathrm{H}, \mathrm{CH}_{3}\right) ;{ }^{13} \mathrm{C}\left\{{ }^{1} \mathrm{H}\right\} \operatorname{NMR}\left(67.8 \mathrm{MHz}, \mathrm{CDCl}_{3}\right) \delta 141.6,128.5,128.3,125.9,34.8,31.8,31.5,31.2,22.0,13.7 ; \mathrm{IR}$ $\left(\mathrm{CHCl}_{3}, \mathrm{NaCl}\right.$ cell, $\left.v_{\max }, \mathrm{cm}^{-1}\right) 3019(\mathrm{C}-\mathrm{H}), 2960(\mathrm{C}-\mathrm{H}), 1603$ (C=C), 1512 (C=C), 1454 (C-H); Anal. Calcd for $\mathrm{C}_{13} \mathrm{H}_{20} \mathrm{~S}$ (208.13): C, 74.94; H, 9.68. Found: C, 74.74; H, 9.65.

1-(1-Buthylthio)indane (3k). The title compound was obtained as a colorless oil (19.0 mg, 31\%). ${ }^{1} \mathrm{H}$ NMR (270 $\mathrm{MHz}_{\mathrm{CDCl}}$ ) $\delta$ 7.21-7.13 (m, 4H, Ar-H), 3.69-3.58 (m, 1H, CH), 3.36-3.27 (m, 2H, $\left.\mathrm{CH}_{2}\right), 2.98-2.89\left(\mathrm{~m}, 2 \mathrm{H}, \mathrm{CH}_{2}\right)$, $2.61(\mathrm{t}, J=7.4 \mathrm{~Hz}, 2 \mathrm{H}, \mathrm{CH}), 1.67-1.55\left(\mathrm{~m}, 2 \mathrm{H}, \mathrm{CH}_{2}\right), 1.50-1.36\left(\mathrm{~m}, 2 \mathrm{H}, \mathrm{CH}_{2}\right), 0.93\left(\mathrm{~d}, J=7.2 \mathrm{~Hz}, 3 \mathrm{H}, \mathrm{CH}_{3}\right) ;{ }^{13} \mathrm{C}\left\{{ }^{1} \mathrm{H}\right\}$ NMR $\left(67.8 \mathrm{MHz}_{2} \mathrm{CDCl}_{3}\right) \delta 141.9,126.5,124.3,43.3,40.7,31.9,31.3,22.1,13.7 ; \mathrm{IR}\left(\mathrm{CHCl}_{3}, \mathrm{NaCl}\right.$ cell, $\left.v_{\max }, \mathrm{cm}^{-1}\right)$ 2930 (C-H), 2873 (C-H), 1460 (C-H), 1273 (SC-H); Anal. Calcd for $\mathrm{C}_{13} \mathrm{H}_{18} \mathrm{~S}$ (206.35): C, 75.67; H, 8.79. Found: C, $75.63 ; \mathrm{H}, 8.82$.

\section{Acknowledgements}

This work was supported by The Foundation for Japanese Chemical Research and Daicel Corporation

\section{Supplementary Material}

Copies of the ${ }^{1} \mathrm{H}$ NMR and ${ }^{13} \mathrm{C}$ NMR Spectra are provided. This material is available free of charge via the Internet at http://xxxxxx

\section{References}

1. Comprehensive Organic Synthesis; Trots, B. M., Fleming, I., Eds.; Pergamon Press Ltd.: New York, 1991, Vol. 4. 
2. Krief, A. In Comprehensive Organometallic Chemistry II; Abel, E. W., Stone, F. G. A., Wilkinson, G. Eds.; Pergamon Press Ltd.: New York, 1995, Vol. 11, Chapter 13.

3. Metal-Catalyzed Cross-Coupling Reactions, Eds.: Meijere, A.; Diederich, F. Eds.; Wiley-VCH: Weinheim, 2004.

4. Metzner, P.; Thuillier, A.; Sulfur Reagents in Organic Synthesis; Katritzky, A. R.; Meth-Cohn, O.; Rees, C. W. Eds.; Academic Press: San Diego, 1994.

5. Ley, S. V.; Thomas, A. W. Angew. Chem. Int. Ed. 2003, 42, 5400. https://doi.org/ 0.1002/anie.200300594

6. Ipatieff, V. N.; Pines, H.; Friedman, B. S. J. Am. Chem. Soc. 1938, 60, 2731. https://doi.org/10.1021/ja01278a055

7. Screttas, C. G.; Micha-Screttas, M. J. Org. Chem. 1979, 44, 713. https://doi.org/10.1021/jo01319a011

8. Wolff, F.; Finke, H. Z. Chem. 1972, 12, 180.

9. Posner, T. Chem. Ber. 1905, 38, 646. https://doi.org/10.1002/cber.190503801106

10. Savolainen, M. A.; Wu, J. Org. Lett. 2013, 15, 3802. https://doi.org/10.1021/ol4015909

11. Mukaiyama, T.; Izawa, T.; Saigo, K.; Takei, H. Chem. Lett. 1973, 355. https://doi.org/10.1246/cl.1973.355

12. Belley, M.; Zamboni, R. J. Org. Chem. 1989, 54, 1230. https://doi.org/10.1021/jo00266a053

13. Curran, D. P. ; Martin-Esker, A. A. ; Ko, S. B. ; Newcomb, M. J. Org. Chem. 1993, 58, 4691. https://doi.org/10.1021/jo00069a036

14. Tyson, E. L. ; Ament, M. S.; Yoon, T. P. J. Org. Chem. 2013, 78, 2046. https://doi.org/10.1021/j03020825

15. Tyson, E. L.; Niemeyyer, Z. L.; Yoon, T. P. J. Org. Chem. 2014, 7, 1427. https://doi.org/10.1021/jo500031g

16. Bhat, V. T.; Duspara, P. A.; Seo, S.; Bakar, N. S. B. A.; Greaney, M. F. Chem. Commun. 2015, 51, 4383. https://doi.org/10.1039/C4CC09987G

17. Weïwer, M.; Coulombel, L.; Duñach, E. Chem. Commun. 2006, 332. https://doi.org/10.1039/B513946E

18. Weïwer, M.; Chaminade, X.; Bayón, J. C.; Duñach, E. Eur. J. Org. Chem. 2007, 2464. https://doi.org/10.1002/ejoc.200601112

19. Weïwer, M.; Duñach, E. Tetrahedron Lett. 2006, 287. https://doi.org/10.1016/i.tetlet.2005.11.030

20. Taichi, T.; Ogawa A. J. Org. Chem. 2014, 79, 5028. https://doi.org/10.1021/j0500586a

21. Xi, H.; Ma, E.; Li, Z. Tetrahedron 2016, 72, 4111. https://doi.org/10.1016/i.tet.2016.05.050

22. Kanagasabapathy, S.; Sudalai, A.; Benicewicz, B. C. Tetrahedron Lett. 2001, 42, 3791. https://doi.org/10.1016/S0040-4039(01)00570-6

23. Taniguchi, N. J. Org. Chem. 2020, 85, 6528. https://doi.org/10.1021/acs.joc.0c00487

24. Taniguchi N. ChemistrySelect 2018, 3, 6209. 
https://doi.org/10.1002/slct.201801472

25. Taniguchi, N.; Kitayama, K. Synlett 2018, 29, 2712.

https//doi.org/10.1055/s-0037-1610302

26. March's Advanced Organic Chemistry $5^{\text {th }}$ Ed.; Smith, M. B., March, J., Eds.; John Wiley \& Sons, Ltd.: Canada, 2001.

This paper is an open access article distributed under the terms of the Creative Commons Attribution (CC BY) license (http://creativecommons.org/licenses/by/4.0/) 